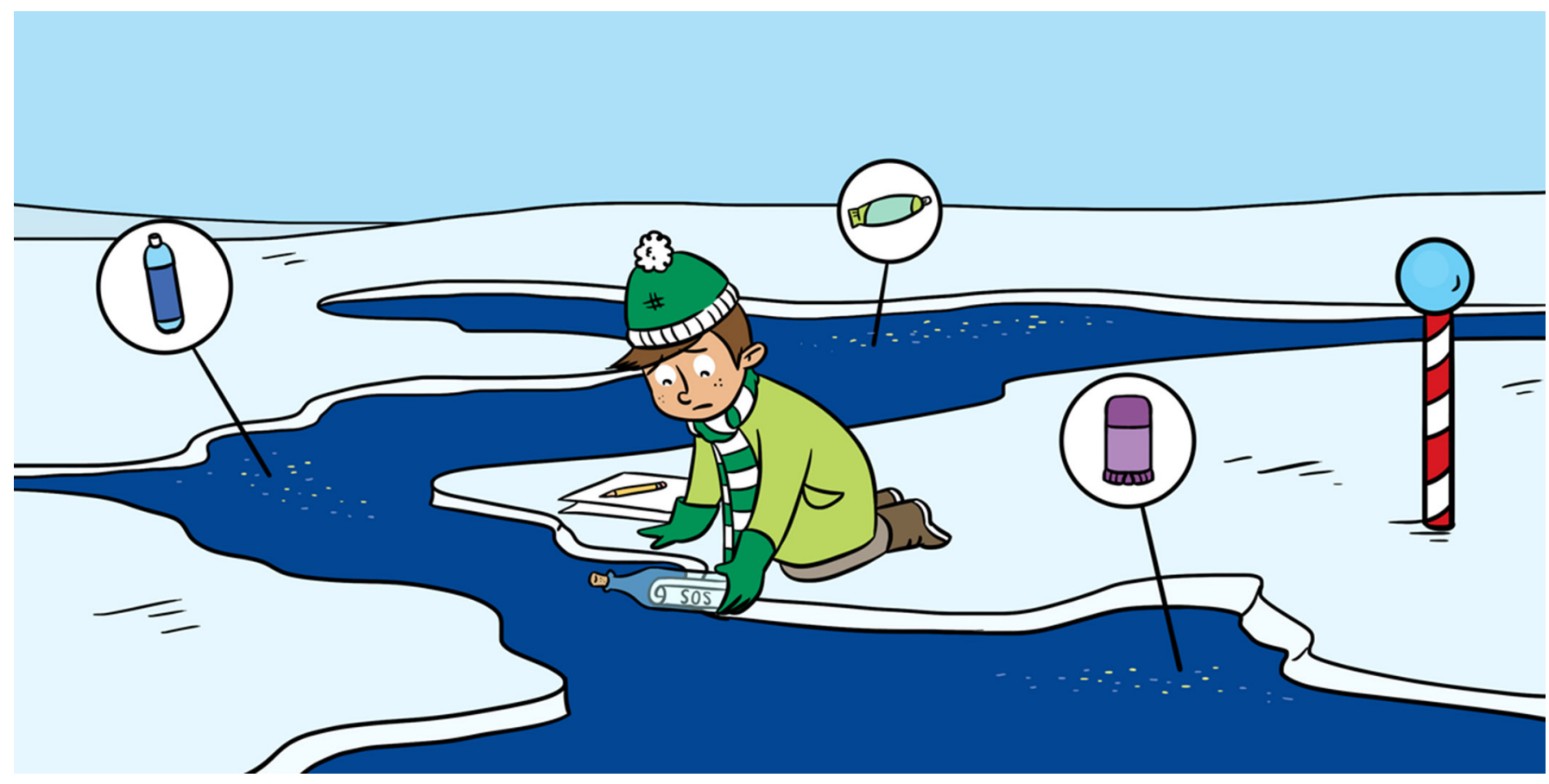

\title{
A MESSAGE IN A BOTTLE FROM THE NORTH POLE-HOW PLASTIC POLLUTES THE ARCTIC OCEAN
}

\author{
Lisa W. von Friesen ${ }^{1 *}$, Nanna B. Hartmann ${ }^{2}$, Geir W. Gabrielsen ${ }^{3}$ and Sinja Rist ${ }^{2,4^{*}}$ \\ ${ }^{1}$ Marine Biology Section, University of Copenhagen, Copenhagen, Denmark \\ ${ }^{2}$ Department of Environmental Engineering, Technical University of Denmark, Kongens Lyngby, Denmark \\ ${ }^{3}$ Norwegian Polar Institute, Tromsø, Norway \\ ${ }^{4}$ National Institute of Aquatic Resources, Technical University of Denmark, Kongens Lyngby, Denmark
}

\section{YOUNG REVIEWERS:}

EXPANDING YOUR HORIZONS AGES: $12-15$
Did you know that plastic waste is so widespread across our planet that it can be found even in the far north, in the Arctic Ocean? Plastic ends up in the environment in many different ways, and researchers are trying to figure out how this pollution affects the animals and plants living in environments that contain plastic waste. Here comes a message in a bottle from the North Pole, telling you a story about tiny pieces of plastic in the Arctic Ocean. How is it even possible for plastic waste to reach the Arctic Ocean? What happens to the plastic once it is there? Is the plastic harming Arctic animals? And how can we prevent plastic pollution? Join us on a chilling story about plastic pollution in our northernmost waters: the fascinating Arctic Ocean. 


\section{WHY IS PLASTIC POLLUTING THE OCEANS?}

Plastic waste, also called plastic litter, is found in all oceans around the world-even as far north as the Arctic. But how does plastic get there? Let us start by looking at where plastic comes from. Have you thought about how many plastic items you use each day? Your toothbrush, water bottle, computer, and many clothes are likely made at least partly of plastic. But what is plastic? Plastic is the general name for a group of many different artificial materials, which is why plastic can have so many different properties and applications. Since we need plastic for many products, extremely high amounts of plastic are produced. Plastic products eventually wear out and become waste. Even though we try to collect, reuse, and recycle plastic waste, a very large amount of it is lost and ends up in the oceans. Maybe you have noticed that it is almost impossible to walk along a beach without finding plastic litter, like water bottles?

Plastic litter is not only found on beaches. It is everywhere in the oceans: floating on the surface, suspended in mid-level water, and lying on the seafloor. The majority of the plastic in the oceans comes from land, most from direct littering and mismanaged waste. This plastic litter is transported to the ocean by the wind or along rivers. Much plastic is also discarded directly at sea, for example abandoned fishing gear. Once in the environment, plastic litter starts breaking down into smaller pieces, but it takes hundreds of years for the plastic pieces to fully disappear. When the pieces have reached the size of a few millimeters or less, they are called microplastics. Sometimes microplastics are even produced intentionally, for use in soaps and toothpastes for example, and they can reach the environment when they are washed down the drain with the wastewater we produce in our homes [1].

\section{HOW MICROPLASTICS TRAVEL THE WORLD'S OCEANS}

Water coming from the drains of our homes and industries. Wastewater can be treated (cleaned) before it is released back to the ocean, lakes, or rivers.

Once microplastics reach the oceans, many different things can happen to them. If the plastic material is heavy, it can sink to the seafloor. Plastic can also become heavier and sink if animals, plants, or bacteria start growing on it. If the plastic material is light and floats in water, ocean currents can transport it over long distances [1]. All oceans on Earth are connected by water currents. Our smallest ocean, the Arctic Ocean, is a place that may seem far away, but microplastics are found even there. Aside from plastic pollution, the Arctic is also a region where climate change acts very quickly and where other environmental pollutants accumulate in high amounts. Many researchers are interested in the Arctic and hope to better understand how we humans impact the world's oceans.

The Arctic Ocean is mostly surrounded by land. Water enters the Arctic Ocean from the Atlantic and Pacific Oceans (Figure 1), as well as 


\section{Figure 1}

Plastic litter is transported to the Arctic Ocean with water currents (orange) from the Atlantic and Pacific Oceans, and also with air currents. Plastic waste also comes from local landand/or sea-based sources within the Arctic [2].

\section{SEA ICE}

Ice that is formed when seawater freezes.

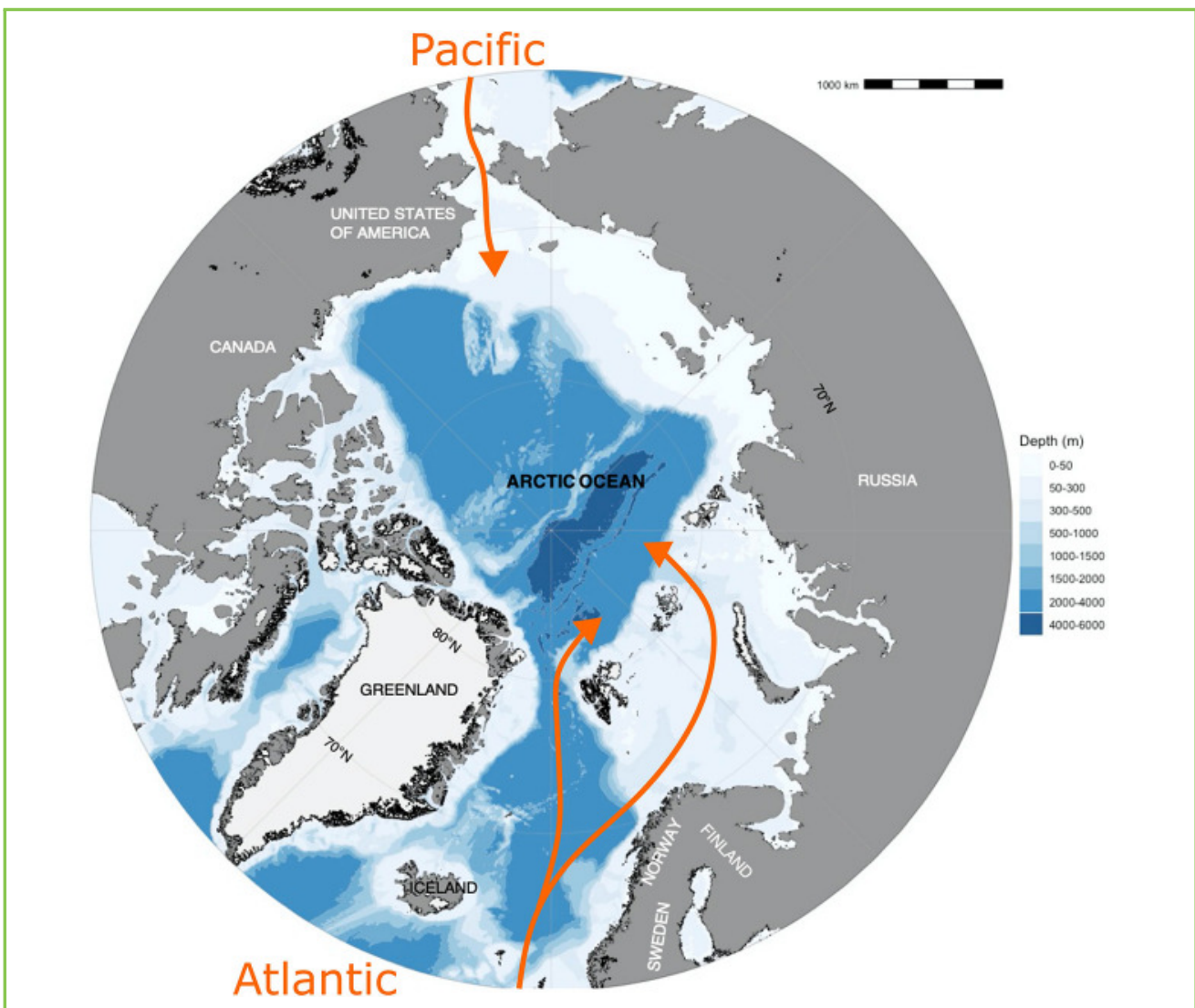

Figure 1

from large rivers, precipitation (snow and rain), and through meltwater from glaciers. Through these water sources, microplastics from more populated areas can reach the Arctic. Small microplastics can also be transported in the air (Figure 2). Similar to ocean currents, air currents circulating around Earth can transport small microplastics great distances. But not all microplastics in the Arctic come from faraway places. There are also sources of plastic litter and microplastics in the Arctic itself (Figure 2) [3]. About 4 million people live in the Arctic, and many tourists visit this area. Wastewater treatment is not common in the Arctic, which means that plastic litter and microplastics more easily reach the environment and the ocean through untreated wastewater. There are also industries in the Arctic, both at sea and on land, that generate plastic pollution. Plastic from fishing activities, for example, is commonly found on Arctic beaches.

\section{THE ARCTIC OCEAN: POLAR BEARS, ICE AND... PLASTIC?!}

Now that you know how microplastics end up in the Arctic Ocean, you might wonder where within the ocean they go. To find out, researchers collected samples of water, seafloor sediments, organisms, and ice, and carefully analyzed them for microplastics. They detected microplastics in seawater, sediment, sea ice, snow, on beaches, and 
Figure 2

Microplastics (orange dots) move through the environment and interact with animals in the Arctic Ocean. They reach the ocean from land and air (orange dotted arrows), or they are released from ships at sea. In the ocean. most microplastics sink to the seafloor over time. Animals like zooplankton or mussels can ingest microplastics (orange solid arrows) directly from the water and worms can ingest them in sediment. Other animals can take up microplastics by eating prey that has previously ingested microplastics (black arrows). Microplastics can also be excreted after animals have eaten them.

\section{TROPHIC TRANSFER}

Transfer of substances and/or particles, like microplastics, from the body of a prey organism to that of a predator, when the prey is eaten.

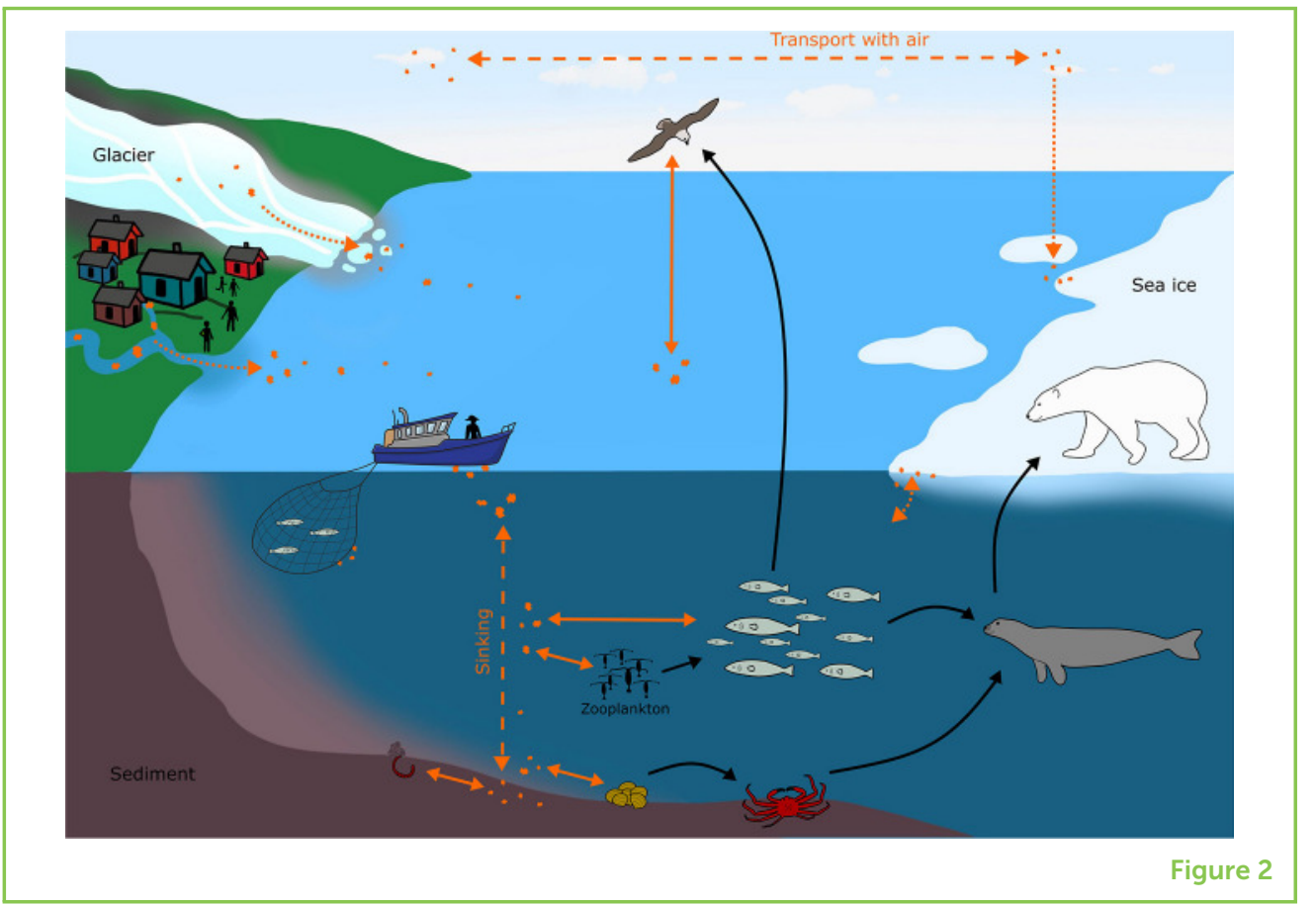

even inside animals from the Arctic Ocean [4]. Especially high amounts were found within sea ice. Sea ice forms from seawater, in contrast to glacial ice that forms from snow or freshwater. The Arctic Ocean has a large floating cover of sea ice, but due to climate change that cover is decreasing rapidly. When sea ice melts in the summer, the microplastics within it are released into the seawater, where many organisms are present at that time of the year [3]. Sea ice is often covered with snow. Microplastics found in Arctic snow were probably transported in the air and settled with snow, rain, or just by gravity.

Microplastics in the Arctic Ocean have been found both far from shore and at the coasts. The amounts of microplastics in seawater close to some towns are higher than the amounts found further away, which tells us that microplastics might spread from the towns. Researchers have detected microplastics in fish, seabirds, starfish, crabs, and mussels in the Arctic Ocean. The northern fulmar, an important seabird in the Arctic, is known to be especially affected by plastic. It remains to be determined whether polar bears have microplastics in their bodies.

\section{DO MICROPLASTICS HARM ANIMALS?}

Animals can ingest microplastics accidentally as they eat their normal food. This can happen if they drink plastic-containing water or if their prey contain microplastics. For example, if a crab eats a mussel that has already ingested microplastics, the microplastics in the mussel are moved into the crab (Figure 2). This is called trophic transfer. 
Figure 3

(A) Some microplastics carry harmful chemicals from their production, which can get released and come into contact with animals. (B)

Microplastics can also collect harmful chemicals from the water and together they can be ingested by animals. (C) When an animal has harmful chemicals in its body and ingests clean microplastics, the plastics can sometimes collect those chemicals and they are excreted together.

\section{ZOOPLANKTON}

Small animals, some of which are microscopic in size, that drift in oceans, lakes, and rivers.

\section{EXCRETION}

Release of waste products, such as urine and feces, from an organism.
A

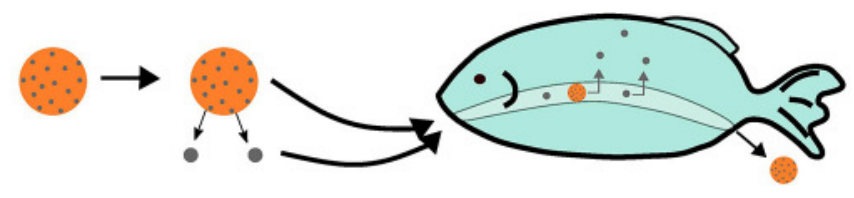

B

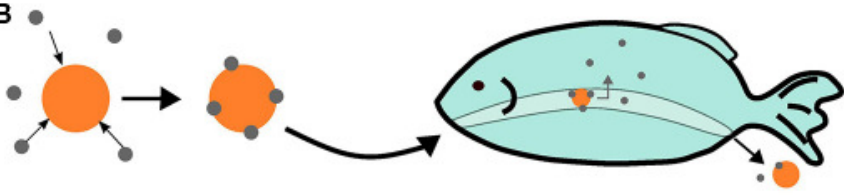

c

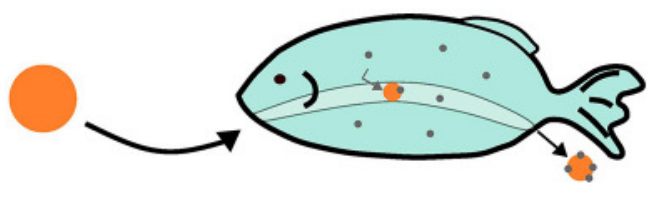

Figure 3

Animals can also ingest microplastics directly, by mistaking them for food. When animals ingest microplastics, the tiny particles might harm them. Researchers have observed this in experiments performed in laboratories. For example, zooplankton, which are very small animals in the oceans, ate less of their normal food when a lot of microplastics were present, because their stomachs were partly filled with plastic particles. Since microplastics do not provide nutrition, animals eating microplastics cannot grow as much as animals eating normal food [5].

Negative effects on animals can also come from chemicals that microplastics sometimes carry (Figure 3) [6]. Chemicals are used in almost any product you can think of. Although many are useful, some chemicals can be harmful to organisms. Harmful chemicals should be prevented from entering the environment. Many different chemicals are added to plastics during production, to make the plastics more flexible or give them color, for example. In the environment, these chemicals can be released from the plastics and come into contact with organisms (Figure 3A). Microplastics can also "collect" chemicals in nature, because certain chemicals in water can easily stick to the plastics (Figure 3B). If animals ingest these chemical-coated microplastics, the harmful chemicals can get into the animals. Surprisingly, this can also work in reverse: if an animal already has many chemicals in its body, then ingesting clean microplastics can actually help to "catch" some of the chemicals and remove them from the animal when the microplastics are excreted (Figure 3C).

A lot of this sounds pretty bad. Does this research mean that all animals in the Arctic are suffering ill effects from microplastics? No, most likely not. The amounts of microplastics that we find in the Arctic are much lower than the amounts that cause harmful effects in laboratory experiments. In addition, most of these experiments were done with 
animals from other parts of the world, not Arctic animals. So we still know very little about the possible effects of microplastics in the Arctic, but we do know that microplastics do not belong there.

\section{CONCLUSIONS}

The Arctic is a unique and vulnerable ecosystem, and is already under a lot of pressure from climate change, which is rapidly causing dramatic changes there. Human activity is also increasing in the Arctic, which is increasing the input of pollutants such as chemicals and microplastics. On top of climate change and chemical pollution, microplastics could be an additional threat that intensifies the total pressure on the Arctic ecosystem. We need to do more research to better understand the amount of microplastics present in the Arctic and the effects that these substances have. In the meantime, we all need to take action against the accumulation of plastic litter in our oceans, before it increases even more. Once microplastics are in the ocean, they are virtually impossible to remove and could stay there for centuries to come. Governments and municipalities need to improve their systems for handling plastic waste, including wastewater treatment, plastic waste collection, and recycling. At the same time, we can all help! Avoid buying and using unnecessary plastic products, reuse and recycle plastic items, collect plastic litter from the environment, and tell your friends and family all about what you have learned in this article. Let us spread this message in a bottle to work together for a future Arctic Ocean without plastic pollution!

\section{REFERENCES}

1. Alimba, C. G., and Faggio, C. 2019. Microplastics in the marine environment: current trends in environmental pollution and mechanisms of toxicological profile. Environ. Toxicol. Pharmacol. 68:61-74. doi: 10.1016/j.etap.2019.03.001

2. Vihtakari, M. 2020. ggOceanMaps: Plot data on oceanographic map using "ggplot2." R package version 0.4.3. Available online at: https://mikkovihtakari.github.io/gg OceanMaps (accessed August 18, 2020).

3. von Friesen, L. W., Granberg, M. E., Pavlova, O., Magnusson, K., Hassellöv, M., Gabrielsen, G. W. 2020. Summer sea ice melt and wastewater are important local sources of microlitter to svalbard waters. Environ. Int. 139:105511. doi: 10.1016/j.envint.2020.105511

4. Halsband, C., and Herzke, D. 2019. Plastic litter in the european arctic : what do we know? Emerg. Contam. 5:308-18. doi: 10.1016/j.emcon.2019.11.001

5. Franzellitti, S., Canesi, L., Auguste, M., Wathsala, R. H. G. R., and Fabbri, E. 2019. Microplastic exposure and effects in aquatic organisms: a physiological perspective. Environ. Toxicol. Pharmacol. 68:37-51. doi: 10.1016/j.etap. 2019.03.009

6. Hartmann, N. B., Rist, S., Bodin, J., Jensen, L. H., Schmidt, S. N., Mayer, P., et al. 2017. Microplastics as vectors for environmental contaminants: exploring 
sorption, desorption, and transfer to biota. Integr. Environ. Assess. Manag.

13:488-93. doi: 10.1002/ieam.1904

SUBMITTED: 02 October 2020; ACCEPTED: 22 July 2021;

PUBLISHED ONLINE: 12 August 2021.

EDITED BY: Carolyn Scheurle, Institut de la Mer de Villefranche (IMEV), France

CITATION: von Friesen LW, Hartmann NB, Gabrielsen GW and Rist S (2021) A Message in a Bottle From the North Pole-How Plastic Pollutes the Arctic Ocean. Front. Young Minds 9:613577. doi: 10.3389/frym.2021.613577

CONFLICT OF INTEREST: The authors declare that the research was conducted in the absence of any commercial or financial relationships that could be construed as a potential conflict of interest.

COPYRIGHT (c) 2021 von Friesen, Hartmann, Gabrielsen and Rist. This is an open-access article distributed under the terms of the Creative Commons Attribution License (CC BY). The use, distribution or reproduction in other forums is permitted, provided the original author(s) and the copyright owner(s) are credited and that the original publication in this journal is cited, in accordance with accepted academic practice. No use, distribution or reproduction is permitted which does not comply with these terms.

\section{YOUNG REVIEWERS}

\section{EXPANDING YOUR HORIZONS, AGES: $12-15$}

Expanding Your Horizons has been active in Geneva since 2009 with the goal of encouraging girls in the Geneva region to explore STEM careers, and to continue with mathematics and science in school. The non-profit association runs the bi-annual EYH conference, supported by local organizations.

\section{AUTHORS}

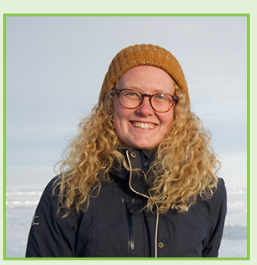

\section{LISA W. VON FRIESEN}

I am a Ph.D. student at the University of Copenhagen. I am really fascinated about the Arctic Ocean and how humans impact it. I study tiny things in the ocean, such as microplastics and microorganisms. I try to better understand where in the Arctic Ocean microplastics and chemicals from plastics are found, and how they got there. I also study how microorganisms (like bacteria) impact the availability of nutrients that bigger organisms in the Arctic Ocean need to grow. I like sailing, horse-back riding and diving. *lisa.vonfriesenabio.ku.dk

\section{NANNA B. HARTMANN}

I am a senior researcher at the Technical University of Denmark. My research is about how small particles, including nanomaterials and microplastics, behave in the environment. I am interested in understanding their distribution, if and how they degrade and how they affect animals. I am also interested in how we can avoid (or 

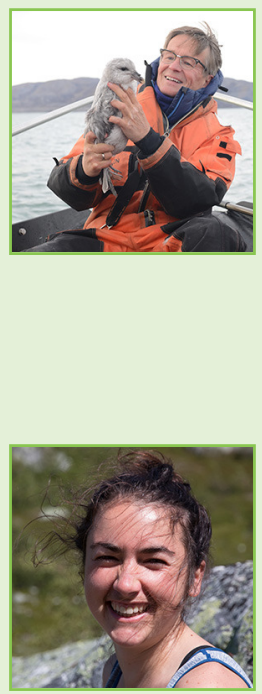

minimize) pollution. At the same time, I am passionate about communication and gender equality in science. I spend my free time on yoga, jewelry making and my family, which includes my husband, two sons, and two cats.

\section{GEIR W. GABRIELSEN}

I am a section leader in toxicology at the Norwegian Polar Institute and professor in biology at The University Center in Svalbard. My research relates to finding new pollutants in the Arctic environment, pollutants in marine food chains, and effects of pollutants on Arctic seabirds. Lately, I have investigated effects of plastic pollution on seabirds and marine mammals. I think communicating my science to young generations is important. I have produced two children's books (Arctic Seabirds and Plastic Sea). A third book about pollutants in the Arctic is under production.

\section{SINJA RIST}

I am a postdoctoral researcher at the Technical University of Denmark and I have been working on microplastics and their interactions with aquatic animals for many years. I am very interested in finding out how pollution from microplastics and chemicals impacts our ecosystems, especially in the changing conditions that come with climate change. I am especially passionate about the ocean and I work with some of the tiniest swimming animals (zooplankton). In my free time I love going diving and snorkeling. *siri@aqua.dtu.dk 